\title{
THE ROLE OF ULTRASOUND IN PREVENTING THE LIFE-THREATENING EMERGENCIES ASSOCIATED WITH REPEATED CESAREAN SECTION
}

\author{
Sucu Roxana ${ }^{1,2}$, Bordeianu Ion ${ }^{1}$ \\ ${ }^{1}$ Ovidius University, Constanta, Romania \\ 2.,Bucur” Maternity, „St. John” Hospital, Bucharest, Romania
}

\section{ORIGINAL PAPER}

Doi: $10.33695 /$ rojes.v2i2.30 Accepted: 05.12.2020

\begin{abstract}
Ultrasonographic evaluation of the hysterorrhaphy scar is an extremely important element in current obstetrical practice, especially in patients who still want a future pregnancy. The purpose of our study was to evaluate the ultrasound findings of the cesarean scar in the third trimester of pregnancy that can reduce the life-threatening emergencies caused by repeated cesarean section such as uterine rupture of abnormal placental adhesions. We conducted a prospective study that included patients who gave birth by caesarean section and presented at a subsequent pregnancy to be monitored during pregnancy. The study was realized during 2016-2020at the Bucur Maternity Hospital, 'Saint John', Bucharest. A number of 57 patients were included in the analyzed group. A number of 12 pregnant women (21\%) monitored both in weeks 30-34 and intraoperatively presented contractions and areas of dehiscence, while 30 (52.6\%) pregnant women showed neither contractions nor areas of dehiscence. Women with contractions had an average scar thickness measured in the third trimester of $3.81 \mathrm{~mm}$ (SD 1.62, CI: [3.32; 4.30]), and those without contractions a thickness of $4.58 \mathrm{~mm}$ (SD 1.25, CI: [3.78; 5.37]. Intraoperatively we identified 3 cases with incomplete uterine rupture. Those cases were previously diagnosed with hysterorraphy scar between $0.15-0.5 \mathrm{~cm}$. The repeated ultrasound evaluation of the cesarean scar is a good predictive factor for the intraoperative quality of the cesarean scar. With the third trimester ultrasound measurement of the uterine scar thickness, the uterine rupture may be avoided.
\end{abstract}

Corresponding author:

SUCU Roxana dr.roxanasucu@gmail.com
Keywords: cesarean scar, uterine rupture, obstetric emergency, scar dehiscence

\section{Introduction}

Worldwide medical organizations are trying to find pregnancy interventions to decrease the number of caesarean interventions. The methods applied are: second opinion before or peer review after a caesarean, better childbirth preparation, more trials of labour after a caesarean, and changes in current financial incentives [1]. The reasons are determined by long-term consequences of the caesarean scar. 
Ultrasonographic evaluation of the hysterorrhaphy scar is an extremely important element in current obstetrical practice, especially in patients who still want a future pregnancy [2]. Thus, the physician can make an early diagnosis of ectopic pregnancy in the uterine scar and can also predict the risks associated with dehiscence that complicates a future cesarean section or birth on a vaginal spotting [1]. The purpose of our study was to evaluate the ultrasound findings of the cesarean scar in the third trimester of pregnancy that can reduce the life-threatening emergencies caused by repeated cesarean section such as uterine rupture of abnormal placental adhesions.

\section{Material and methods}

We conducted a prospective study that included patients who gave birth by caesarean section and presented at a subsequent pregnancy to be monitored during pregnancy. The study was realized during 2016-2020at the Bucur Maternity Hospital, part of the 'Saint John' Clinical Emergency Hospital, Bucharest.

The patients were monitored by ultrasound from the first trimester until birth. We assessed the thickness of the cesarean scar and the association with intraoperative emergency events. In this study, we report the ultrasound evaluation at 30-34 weeks of pregnancy and the frequency of uterine contractions at that gestational age. The originality of the study consists in the evaluation of the life-threatening emergencies such as uterine rupture using previous ultrasound feature.

\section{Results}

An initial analysis of the patients in the study was based on epidemiological features. We included 57 patients in the analysed group. The patients with a scarred uterus were between 18 and 41 yearsof age, with an average of 29.26 years (standard deviation 5.044, CI: [28.45; 30.07]).

The pregnant women who were monitored both in the third trimester, weeks 30-34, and intraoperatively it was observed that the presence of the patent cesarean scar is more frequent in patients who did not present uterine contractions in that period, representing $47.37 \%$ (27 patients) of the analyzed group (Table 1).

\begin{tabular}{|c|c|c|c|c|}
\hline \multicolumn{5}{|c|}{$\begin{array}{l}\text { Uterine contractions }(30-34 \text { weeks }) * \text { Intact } \\
\text { cesarean scar } \\
\end{array}$} \\
\hline \multicolumn{5}{|c|}{ Count } \\
\hline & & \multicolumn{2}{|c|}{$\begin{array}{c}\text { Intact cesarean } \\
\text { scar }\end{array}$} & \multirow[t]{2}{*}{ Total } \\
\hline & & no & yes & \\
\hline \multirow{2}{*}{$\begin{array}{l}\text { Uterine } \\
\text { contractions }\end{array}$} & no & 12 & 27 & 39 \\
\hline & yes & 12 & 6 & 18 \\
\hline Total & & 24 & 33 & 57 \\
\hline
\end{tabular}

Table 1 - Uterine contractions (30-34 weeks) * Intact cesarean scar

It was observed that there is a tendency for patients with contractions in weeks 30-34 to have areas of dehiscence within the cesarean scar. Pregnant women who have presented contractions have an average of 4.14 years from the last pregnancy, respectively 3.04 years in the case of those without pain in the present study. A number of 12 pregnant women out of the $57(21 \%)$ monitored both in weeks 30-34 and intraoperatively presented both contractions and areas of dehiscence, while $30(52.6 \%)$ pregnant women showed neither contractions no areas of dehiscence. To verify the association of the 2 variables, the Chi-square test was used, which indicates an association between the presence of dehiscence zones and contractions in weeks 30-34 (p value <0.05). 


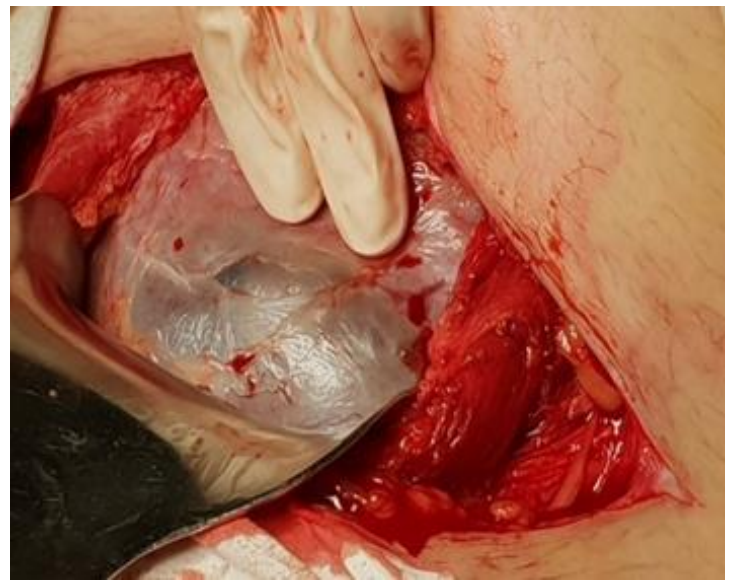

Figure 1 - The intraoperative aspect of incomplete uterine rupture

Thus, pregnant women with contractions have an average scar thickness measured in the third trimester of $3.81 \mathrm{~mm}$ (standard deviation 1.62, CI: [3.32; 4.30]), and those without contractions a thickness of $4.58 \mathrm{~mm}$ (standard deviation 1.25 , CI: [3.78; 5.37]).

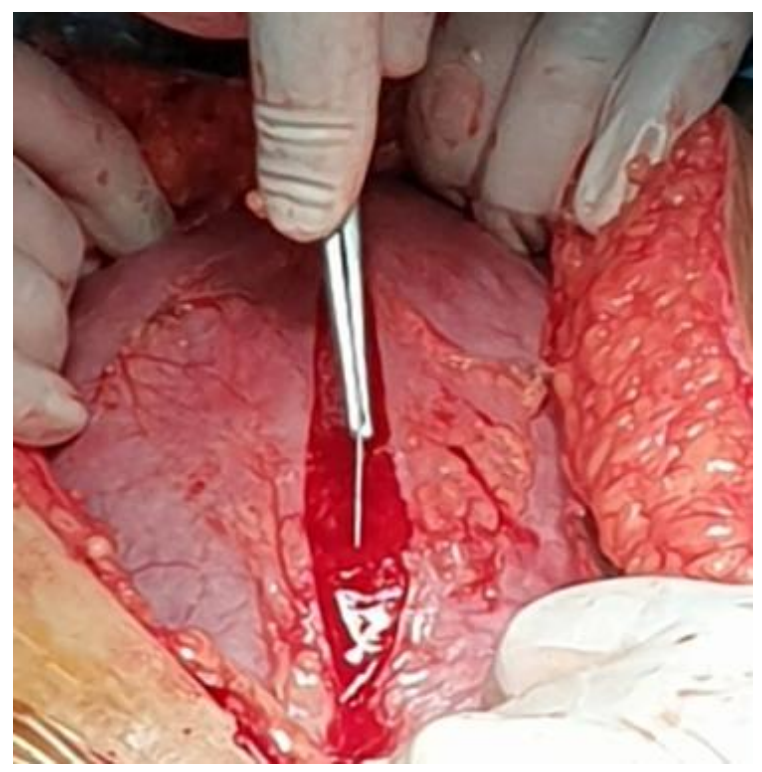

Figures 2 - The intraoperative aspect of placenta increta Figure 2. The medio-corporeal hysterotomy of the uterus because of placenta increta

With that ultrasound evaluation, we had an accurate approach of the patients with a very thin cesarean scar. The patients were monitored more frequently than the others and they were scheduled for cesarean section at 38 weeks of gestation. Intraoperatively we identified 3 cases with incomplete uterine rupture (Figure 1). Those cases were previously diagnosed with hysterorraphy scar between $0.15-0.5 \mathrm{~cm}$.

Another evaluation of the pregnancy included the aspect of the placenta. In the current study, the ultrasound examination before delivery identified $99.4 \%$ of cases of placenta previa. Among them, there were $0.2 \%$ of cases with abnormal adherence of the placenta (Figures 2 and 3). A hemostatic hysterectomy was performed in one case for placenta increta. The intraoperative and postoperative evolution of the patients were favorable.

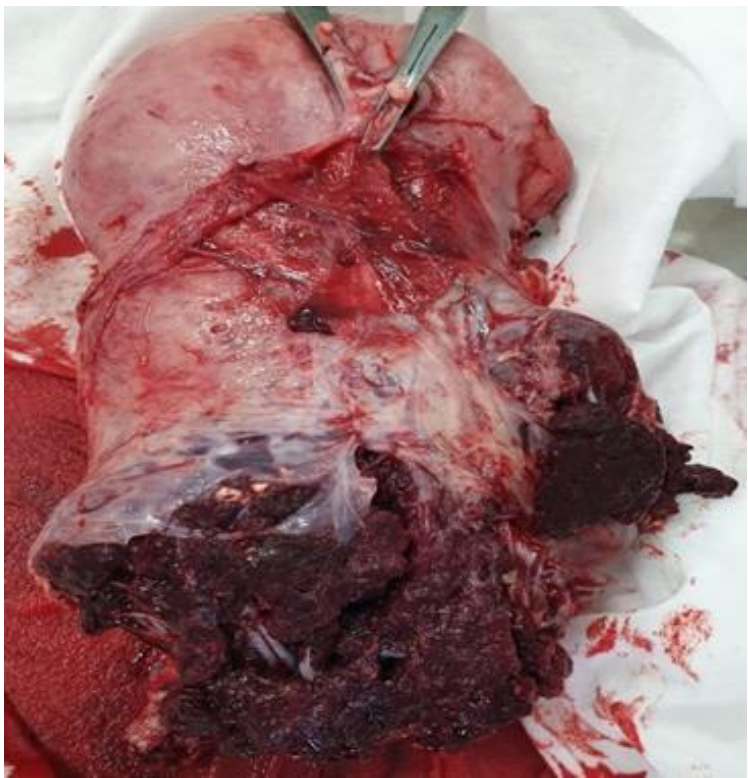

Figure 3 - The surgical specimen of hysterectomy

\section{Discussions}

The measurement of the hysterography scar since the first trimester represents a prognostic factor for the evolution of the pregnancy regarding the risk of uterine rupture. A scar thickness value $<2.5 \mathrm{~mm}$ is associated with an increased risk of uterine dehiscence [3]. A recent study exposes the sonographic characteristics of the lower 
uterine segment in labour in patients with cesarean section. They were found to have a thinner ultrasound segment compared to women without cesarean sections. It is the only reference that can identify similarities with the current study, but the peculiarity of this research is that we have long-term evaluation [4].

Pregnant women who have presented contractions have an average of 4.14 years from the last pregnancy, respectively 3.04 years in the case of those without pain in the present study. This result is a unique aspect, although it is considered that over time the scar becomes more stable. At the same time, the result is justified by the fact that patients are getting older and the possibility of premature birth increases and thus the possibility of uterine contractions [5].

The process of developing the isthmus or niche is multifactorial [6]. The factors that determine the first cesarean section play a crucial role [7]. It is recommended that patients with isthmus benefit from correction before a future pregnancy [7]. The increased number of caesarean operations is directly proportional to the size of the isthmus, but also the tilt of the uterus [8]. The increased size of the niche is associated with symptoms such as metrorrhagia, dysmenorrhea or chronic pelvic pain [9], but the most common symptom is postmenstrual spotting [10]. Hysteroscopic isthmoplasty is the most common method of treatment [11]. The occurrence of ectopic pregnancy in the scar involves several factors [12].

As an attempt to preserve the uterus, after extraction of the fetus and placenta, rapid hysterography in a single or double layer, with slowly absorbable thread for hemostasis, is recommended [13]. Over time, multiple methods of primary hysterography and innovative approaches to saving the uterus have been addressed, which are presented in case reports [14].

Uterine rupture studies often come from countries where pregnant uterine rupture is more common and also include continuity solutions unrelated to delivery by previous cesarean section [15]. Hysterectomy is applied when the uterine defect is irreparable or there is an uncontrollable maternal hemorrhage. The decision to perform a hysterectomy is based on a combination of factors, the patient's intraoperative hemodynamics, including the patient's desire for future pregnancies, the degree of uterine damage, and the obstetrician's ability to repair a complicated rupture [15].

Current studies associate the isthmus with clinical symptoms such as spotting, intermenstrual bleeding, menorrhagia, dyspareunia, dysmenorrhea, or even infertility [16]. Women with a large number of cesarean sections have a higher isthmus and a wider base. Moreover, women with physiologically retrofitted uterus may have a larger niche in the uterine isthmus [12]. The etiopathogeny is the same as in patients with an increased number of uterine scars: decreased local infusion. At the level of the isthmus in the area of hysterography appears an accentuated fibrosis evaluated at the microscopic examination [17]. Besides, pregnancy in the uterine scar has a growing incidence [18].

The myometrium at the scar of the caesarean section is thicker after double-layer hysterography compared to the monolayer suture. The same aspect is observed after the elective cesarean section [19]. Single-layer or double-layer sutures are also associated with defects in the hysterography section such as rupture or dehiscence. However, double-layer sutures appear to have a better long-term prognosis [20]. The recommendation is careful monitoring of scars in the following pregnancies in patients with areas of uterine rupture, as there is a risk of recurrence [21].

\section{Conclusions}

The repeated ultrasound evaluation of the cesarean scar is a good predictive factor for the intraoperative quality of the cesarean scar. 
With the third trimester ultrasound measurement of the uterine scar thickness, the uterine rupture may be avoided.

\section{References}

[1] 'Medline ${ }^{\circledR}$ Abstract for Reference 7 of "Cesarean delivery: Preoperative planning and patient preparation" - UpToDate'. https://www.uptodate.com/contents/cesareandelivery-preoperative-planning-and-patientpreparation/abstract/7 (accessed Mar. 09, 2021).

[2] A. J. M. Bij de Vaate et al., 'Prevalence, potential risk factors for development and symptoms related to the presence of uterine niches following Cesarean section: systematic review', Ultrasound Obstet. Gynecol. Off. J. Int. Soc. Ultrasound Obstet. Gynecol., vol. 43, no. 4, pp. 372-382, Apr. 2014.

[3] A. Woźniak, K. Pyra, H. R. Tinto, and S. Woźniak, 'Ultrasonographic criteria of cesarean scar defect evaluation', J. Ultrason., vol. 18, no. 73, pp. 162-165, 2018.

[4] P. Uharček, A. Brešt'anský, J. Ravinger, A. Máňová, and M. Zajacová, 'Sonographic assessment of lower uterine segment thickness at term in women with previous cesarean delivery', Arch. Gynecol. Obstet., vol. 292, no. 3, pp. 609612, Sep. 2015.

[5] E. Barzilay et al., 'Sonographic assessment of the lower uterine segment during active labor in women with or without a uterine scar - a prospective study', J. Matern.-Fetal Neonatal Med. Off. J. Eur. Assoc. Perinat. Med. Fed. Asia Ocean. Perinat. Soc. Int. Soc. Perinat. Obstet., vol. 31, no. 14, pp. 1885-1888, Jul. 2018

[6] F. Fuchs, B. Monet, T. Ducruet, N. Chaillet, and F. Audibert, 'Effect of maternal age on the risk of preterm birth: A large cohort study', PloS One, vol. 13, no. 1, p. e0191002, 2018

[7] L. (Lucet) F. van der Voet, A. M. J. B. de Vaate, M. W. Heymans, H. A. M. Brölmann, S. Veersema, and J. A. F. Huirne, 'Prognostic Factors for Niche Development in the Uterine Caesarean Section Scar', Eur. J. Obstet. Gynecol. Reprod. Biol., vol. 213, pp. 31-32, Jun. 2017

[8] B. L. Brahmalakshmy and P. Kushtagi, 'Variables influencing the integrity of lower uterine segment in post-cesarean pregnancy',
Arch. Gynecol. Obstet., vol. 291, no. 4, pp. 755762, Apr. 2015.

[9] Z. C. Frank and A. B. Caughey, 'Pregnancy in Women With a History of Uterine Rupture', Obstet. Gynecol. Surv., vol. 73, no. 12, pp. 703708, Dec. 2018.

[10] P. Szkodziak, A. Stępniak, P. Czuczwar, F. Szkodziak, T. Paszkowski, and S. Woźniak, 'Is it necessary to correct a caesarean scar defect before a subsequent pregnancy? A report of three cases', J. Int. Med. Res., vol. 47, no. 5, pp. 2248-2255, May 2019.

[11] T. Eshkoli, A. Y. Weintraub, J. Baron, and E. Sheiner, 'The significance of a uterine rupture in subsequent births', Arch. Gynecol. Obstet., vol. 292, no. 4, pp. 799-803, Oct. 2015.

[12] C.-B. Wang, W.-W.-C. Chiu, C.-Y. Lee, Y.L. Sun, Y.-H. Lin, and C.-J. Tseng, 'Cesarean scar defect: correlation between Cesarean section number, defect size, clinical symptoms and uterine position', Ultrasound Obstet. Gynecol. Off. J. Int. Soc. Ultrasound Obstet. Gynecol., vol. 34, no. 1, pp. 85-89, Jul. 2009.

[13] X. Zhou, H. Li, and X. Fu, 'Identifying possible risk factors for cesarean scar pregnancy based on a retrospective study of 291 cases', J. Obstet. Gynaecol. Res., vol. 46, no. 2, pp. 272-278, Feb. 2020.

[14] S. Gerli, G. Baiocchi, A. Favilli, and G. C. Di Renzo, 'New treatment option for early spontaneous rupture of a postmyomectomy gravid uterus', Fertil. Steril., vol. 96, no. 2, pp. e97-98, Aug. 2011.

[15] A. Shahid, O. Olowu, G. Kandasamy, C. O'Donnell, and F. Odejinmi, 'Laparoscopic management of a 16-week ruptured rudimentary horn pregnancy: a case and literature review', Arch. Gynecol. Obstet., vol. 282, no. 2, pp. 121125, Aug. 2010

[16] A. Monteagudo, C. Carreno, and I. E. Timor-Tritsch, 'Saline infusion sonohysterography in nonpregnant women with previous cesarean delivery: the "niche" in the scar', J. Ultrasound Med. Off. J. Am. Inst. Ultrasound Med., vol. 20, no. 10, pp. 1105-1115, Oct. 2001

[17] A. Ash, A. Smith, and D. Maxwell, 'Caesarean scar pregnancy', BJOG Int. J. Obstet. Gynaecol., vol. 114, no. 3, pp. 253-263, Mar. 2007.

[18] C.-B. Wang and C.-J. Tseng, 'Primary evacuation therapy for Cesarean scar pregnancy: 
three new cases and review', Ultrasound Obstet. Gynecol., vol. 27, no. 2, pp. 222-226, 2006 [19] J. Glavind, L. D. Madsen, N. Uldbjerg, and M. Dueholm, 'Ultrasound evaluation of Cesarean scar after single- and double-layer uterotomy closure: a cohort study', Ultrasound Obstet. Gynecol., vol. 42, no. 2, pp. 207-212, 2013

[20] A. Di Spiezio Sardo, G. Saccone, R. McCurdy, E. Bujold, G. Bifulco, and V. Berghella, 'Risk of Cesarean scar defect following single- vs double-layer uterine closure: systematic review and meta-analysis of randomized controlled trials', Ultrasound Obstet. Gynecol. Off. J. Int. Soc. Ultrasound Obstet. Gynecol., vol. 50, no. 5, pp. 578-583, Nov. 2017.

[21] S. I. Stegwee et al., 'Uterine caesarean closure techniques affect ultrasound findings and maternal outcomes: a systematic review and metaanalysis', BJOG Int. J. Obstet. Gynaecol., vol. 125, no. 9 , pp. 1097-1108, Aug. 2018 